\title{
CURRÍCULO, ARTE-EDUCAÇÃO E CULTURA VISUAL: ARTICULAÇÕES E DESDOBRAMENTOS NA CONTEMPORANEIDADE
}

\author{
CHAGASTELLES, Gianne Maria Montedônio ${ }^{1}$ \\ ARCURI, Christiane de Faria Pereira ${ }^{2}$
}

\begin{abstract}
RESUMO
O texto aponta para os estudos da cultura visual na contemporaneidade como um parâmetro para a atualização dos conteúdos curriculares e processos metodológicos do ensino de artes na escola. Propõe a alfabetização estética dos alunos e a discussão da imagem como conjunto de estímulos visuais que devem ser apreendidos como núcleo central do currículo para a educação e a humanização do sujeito. Considera-se a transmissão da cultura visual do cotidiano para o conhecimento crítico das manifestações artísticas ao longo dos tempos e as articulações com as especificidades dos conteúdos da área de artes. Desse modo, os repertórios imagéticos agem como fundamentos culturais para a flexibilização das formas de diálogo entre a construção da cidadania dos alunos e suas dinamizações estéticas.
\end{abstract}

PalavRas-chave: Currículo - Arte-educação - Cultura visual - Contemporaneidade.

\begin{abstract}
The text points to the study of visual culture in the contemporary world as a parameter for updating curricula and methodological processes of arts education in school. Proposes the aesthetic literacy of students and the image of the discussion as a set of visual stimuli that should be seized as a core curriculum for education and humanization of the subject. It is considered the transmission of visual everyday culture to critical knowledge of artistic events throughout the ages and the joints with the specificities of the arts district of content. Thus, the pictorial repertoires act as cultural foundations for flexible forms of dialogue between the construction of the citizenship of students and their aesthetic dynamizations.
\end{abstract}

KeYWORDS: Curriculum - Art-education - Visual culture - Contemporaneity.

\footnotetext{
${ }^{1}$ Professora Adjunta de Artes Visuais do Instituto de Aplicação Fernando Rodrigues da Silveira (CAp-UERJ) e do Instituto de Artes (IARTS) da Universidade do Estado do Rio de Janeiro. Email: giannem@globo.com

${ }^{2}$ Professora Adjunta de Artes Visuais do Instituto de Aplicação Fernando Rodrigues da Silveira (CAp-UERJ) e do Instituto de Artes (IARTS) da Universidade do Estado do Rio de Janeiro. Email: arcuriarte@gmail.com
} 
e-Mosaicos - Revista Multidisciplinar de Ensino, Pesquisa, Extensão e Cultura do Instituto de Aplicação Fernando Rodrigues da Silveira (CAp-UERJ)

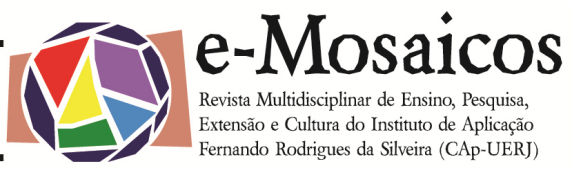

Para que haja a formação dos currículos em Artes Visuais e História da Arte na escola, nos ensinos fundamental e médio, é necessário responder a um questionamento que fundamenta a atividade pedagógica atual. Qual a contribuição específica que as artes visuais trazem para a educação e a humanização do sujeito? 0 mundo atual caracteriza-se, entre outros aspectos, pelo contato com imagens, cores e luzes em quantidades inigualáveis na história. Grande parte da nossa aprendizagem informal se realiza através da imagem. Segundo os Parâmetros Curriculares Nacionais, "a criação e a exposição às múltiplas manifestações visuais geram a necessidade de uma educação para saber ver e perceber, distinguindo sentimentos, sensações, ideias e qualidades contidas nas formas e nos ambientes" (BRASIL,1998a). Por isso é importante que estas reflexões estejam incorporadas na escola, nos currículos das aulas de artes visuais. Há a necessidade de nos preocuparmos com a alfabetização estética de nossos alunos, pois vivemos num mundo dominado pela linguagem visual. Assim, com a alfabetização estética, o aluno deixa de ser passivo e aprende a ser crítico em relação ao mundo das imagens, a discernir as imagens artísticas das do senso comum. Fernando Hernández escreve que "a imagem, como conjunto de estímulos visuais, é o núcleo central do novo currícuIo" (HERNÁNDEZ , 2000, p. 79).

Os Parâmetros Curriculares Nacionais em artes visuais (BRASIL,1998a) sugerem uma abordagem ampliada em relação ao ensino de Arte na escola, começando pela terminologia Artes Visuais, ao invés de Artes Plásticas. As artes visuais, além das formas tradicionais abordadas pelas artes plásticas - pintura, escultura, desenho, gravura, arquitetura, objetos, cerâmica, entalhe - incluem outras modalidades (inclusive audiovisuais) que resultam dos avanços tecnológicos e transformações estéticas do século $X X$, como fotografia, moda, artes gráficas, desenho em computador, desenho industrial, arte em computador, videoarte, televisão, cinema de animação, multimídia artística, performance, videoclipe, museu virtual e arte na rede. Para ensinar estas modalidades das artes visuais, é necessário utilizar diferentes meios, materiais, suportes, tecnologia digital para se aproximar da realidade contemporânea em que o aluno está inserido. Os modos de produção e de conhecimento da imagem são bastante diversificados. Entretanto, esses instrumentos de produção artísticos não devem ter um fim em si mesmo, mas são meios para poder ver, significar e produzir arte e percepções do mundo.

As vivências artísticas em artes visuais e audiovisuais experienciadas pelo aluno fora da escola devem ser consideradas como ponto de referência para os novos estudos dentro do ambiente escolar. Essa atual orientação curricular se inspira nas tendências da cultura visual sobre educação estética, trabalhando tanto com as obras da História da Arte, quanto com a produção artística do aluno e a de seus colegas, com a estética do cotidiano, com as tecnologias da informação (as imagens publicitárias, filmes e outdoors), com 0 espaço urbano, com a produção de grupos locais, com a arte popular, com a arte de diferentes povos e de diferentes regiões. As referências à arte no currículo devem vir de uma série de lugares, de dentro e de fora da escola. Assim, é pelo intercruzamento de padrões estéticos populares e eruditos que os conteúdos a serem trabaIhados podem levar o aluno ao conhecimento da própria cultura, impulsionar a descoberta da cultura do outro (HERNÁNDEZ, 2000, p. 79) e relativizar as normas e valores da cultura de cada um. Pelo ensino da arte não se pretende a formação de artistas e sim a formação de cidadãos que possam ser fruidores, conhecedores e decodificadores das imagens.

A inserção da cultura visual no currículo de 
e-Mosaicos - Revista Multidisciplinar de Ensino, Pesquisa, Extensão e Cultura do Instituto de Aplicação Fernando Rodrigues da Silveira (CAp-UERJ)

artes pretende articular os conteúdos narrativos às suas respectivas leituras críticas. A educação em arte deve difundir a cultura visual que circula cotidianamente na vivência do aluno afim de que ele seja capaz de argumentar crítica e esteticamente sobre a massificação imagética. Articulamos a difusão da cultura visual da contemporaneidade no ensino de artes de modo que consigamos justificar o quanto o cotidiano é preponderante e interessante para a compreensão das manifestações artísticas ao longo dos tempos; da mesma forma em que o aluno possa se reconhecer como parte desse processo de aculturação.

Deste modo, a educação da cultura visual pode ser compreendida enquanto uma ampla atitude em relação ao mundo, à sociedade, ao outro, às práticas culturais e, sobretudo, como diz Hernández (2013), a uma "metodologia viva" que dinamiza os questionamentos e a vontade de continuar aprendendo. Identificar imagens e elementos visuais do cotidiano como correspondentes temporais de diferentes culturas pressupõe identificar e valorizar a dimensão cultural da própria imagem e suas relações de significados inerentes à conjuntura no qual foram produzidos. Em outras palavras, as imagens e demais elementos visuais suscitam possíveis diálogos alegóricos, quer dizer, agem como receptores circunstanciais e circulantes na cultura cotidiana, apesar de fazerem referências às culturas anteriores. A interpretação dos significados alegóricos ou mesmo a conotação simbólica das imagens da contemporaneidade são inapropriadas se não estabelecerem relações com as demais imagens de referências culturais de demais períodos antecedentes. Vale destacar que ruptura e ressignificação, no desenvolvimento artístico-pedagógico com imagens visuais, devem estar estritamente relacionadas, porque apontam para a decorrente pluralidade cultural das formas subjetivas de ver e lidar com o mundo na/da escola e, sobretudo, com a realida- de social do aluno.

Culturas das imagens, culturas do entretenimento, culturas escolares e culturas digitais são alguns dos exemplos de efemeridades, constituídas por formas visuais e conceituais híbridas que nos assediam cotidianamente e que buscamos compreender. São formas cambiantes, formas mutantes de modalidades identitárias provisórias, oriundas de ou expostas a nomadismos culturais dependentes dos processos de mundialização que habitam o panorama contemporâneo. Essas formas trazem no seu bojo questões estéticas, plásticas, culturais, tecnológicas e educacionais que nos defrontam e nos desafiam. O que nos leva a questionar e problematizar como, em algumas realidades escolares, o currículo do ensino de artes pode manter-se alheio a tanto dinamismo cultural, ainda hoje.

O currículo e os conteúdos gerais para o ensino de artes (visuais) nos PCNs, contudo, são pautados em três eixos de articulação sistematizados por Ana Mae Barbosa (BARBOSA, 2012), na Proposta Triangular: fazer/ler/contextualizar. $\mathrm{O}$ ensino de Arte é trabalhado em suas dimensões de criação, leitura, comunicação, constituindo-se em um espaço de reflexão e diálogo, e possibilitando aos alunos entender e posicionar-se diante de conteúdos artísticos, estéticos e culturais. Produzir refere-se ao fazer artístico, como expressão, construção e representação. 0 ato de produzir realiza-se por meio da experimentação e uso das linguagens artísticas. Ler a imagem refere-se ao âmbito da recepção, incluindo percepção, decodificação, interpretação, fruição de arte e do universo a ela relacionado. Contextualizar é situar o conhecimento do próprio trabaIho artístico, dos colegas e da arte como produto social e histórico, o que desvela a existência de múltiplas culturas e subjetividades.

Assim, as aulas de artes visuais não envolvem só o fazer, como na Escola 
Nova, mas também o ler e o contextualizar as obras. À diferença do método da Escola Nova e do Modernismo (BARBOSA, 2011, p.34), que priorizava a emoção como ponto central da aprendizagem da arte, os métodos na contemporaneidade apontam para a cognição (BARBOSA, 2013, p.33) em que a arte passou também a priorizar a elaboração e não apenas a originalidade. A pedagogia contemporânea considera a arte não apenas como expressão, mas também como cultura, apontando para a contextualização histórica e do aprendizado da gramática visual que alfabetize para a leitura da imagem. Logo, os três eixos de aprendizagem da Proposta Triangular não são uma reação contra as conquistas do modernismo, mas uma ampliação dos princípios de expressão individual que marcaram a modernização do ensino da arte.

Percebe-se, no entanto, que o ensino das artes se expandiu, com o decorrer dos anos, sofrendo intensas mudanças no que diz respeito aos seus objetivos, conteúdos e metodologias. Entretanto, ainda assim, constatamos uma carência bibliográfica no que se refere à pesquisa teórica sobre o ensino das artes. As referências teóricas mais comumente debatidas e recentes ainda são as mesmas do decorrer de duas décadas. Autores como Ana Mae Barbosa (2006), Maria Heloísa Ferraz e Maria Fusari (1993), Miriam Celeste Martins (1998) são as mais relutantes estudiosas no Brasil que permanecem atuantes no aprofundamento sobre o ensino das artes e demais especificidades. Com essas autoras torna-se possível compreender que a concepção de ensino de arte, enquanto um campo de conhecimento, está norteada a partir do interculturalismo, da interdisciplinaridade e da aprendizagem dos conhecimentos artísticos: a inter-relação entre o fazer, a leitura e a contextualização da arte como proposta metodológica.

Nesse sentido, segundo os Parâme- tros Curriculares Nacionais, a elaboração dos conteúdos em artes visuais deve estar pautada nos seguintes critérios:

conteúdos que favoreçam a compreensão da arte como cultura, do artista como ser social e dos alunos como produtores e apreciadores; conteúdos que valorizem as manifestações artísticas de povos e culturas de diferentes épocas e locais, incluindo a contemporaneidade e a arte brasileira; conteúdos que possibilitem que os três eixos da aprendizagem possam ser realizados com grau crescente de elaboração e aprofundamento (BRASIL. 1998a, p51).

Assim, além de articular esses métodos, deve-se chamar a atenção para dois pontos: por um lado, a ruptura com a abordagem tradicional da história da arte, ligada somente à história factual dos acontecimentos, fatos, nomes e datas, sem problemáticas ligadas ao nível conceitual e contextual. Por outro, uma ruptura com a tendência linear, sequencial e evolucionista das formas artísticas através do tempo. Ou seja, um rompimento da abordagem temporal com a ideia de causa e efeito. É importante situar e contextualizar historicamente a obra no tempo, pois nenhuma obra existe no vácuo, mas percebendo a plasticidade temporal na história da arte.

Dentro deste contexto, a cronologia da história da arte deixa de ser o principal vetor de elaboração dos conteúdos curriculares, dando lugar aos temas, às problemáticas e aos projetos articulados. Opera-se o trabalho interdisciplinar por projetos geradores, neste caso, a proposta é trabalhar um objeto por todos os seus ângulos. Constitui uma associação de disciplinas, por conta de um projeto ou de um objeto que Ihes sejam comuns. Assim, não basta praticarmos diferentes tecnologias e modalidades sem um projeto educativo articulado (HERNÁNDEZ, 2000, p. 175-251), ou um tema, ou uma problemática na área. Atividades soltas, sem con- 
e-Mosaicos - Revista Multidisciplinar de Ensino, Pesquisa, Extensão e Cultura do Instituto de Aplicação Fernando Rodrigues da Silveira (CAp-UERJ)

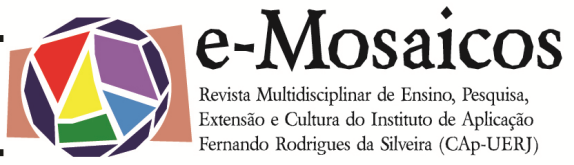

ceitos e ideias artísticas e estéticas levam à banalização do ensino da arte. A seleção dos assuntos, de conceitos e a maneira como são encaminhadas as relações estabelecidas pelo professor é de extrema importância para se alcançar um ensinoaprendizagem significativo em artes. É necessário buscar alternativas mais conceituais, com recortes que eduquem pela experiência da interpretação e não somente pelo sequenciamento cronológico. Um currículo de excelência está comprometido com a aprendizagem do aluno e elaboração de estratégias que garantam que a aprendizagem ocorra. Para tanto, é importante que o conceito faça sentido para o aluno, assim, como nos ensinou Paulo Freire, é necessário que o professor parta da realidade do aluno, de algo do seu interesse. Diz Freire:

A inquietação em torno do conteúdo do diálogo é a inquietação em torno do conteúdo programático da educação. Para o educador-educando, dialógico, problematizador, o conteúdo programático da educação não é uma doação ou uma imposição - um conjunto de informes a ser depositado nos educandos -, mas a devolução organizada, sistematizada e acrescentada ao povo daqueles elementos que este the entregou de forma desestruturada (FREIRE, 2005, p.83).

Por isso, uma educação que apenas pretende transmitir significados que estão distantes da vida concreta do aluno não produz uma aprendizagem significativa. A cada momento de seu desenvolvimento, o aluno poderá apreender conceitos e princípios de modos distintos até que por fim possa, progressivamente, deles se apropriar, compreendendo seus significados mais complexos. A atualização do planejamento e das estratégias de aprendizagem nos currículos de artes nos faz repensar sobre a nossa própria capacidade de flexibilizar as formas de dialogar com a experiência visual dos alunos, tratando os nossos repertórios de imagens e elementos visuais do cotidiano como alicerces de aproximação entre cultura, visualidade, docência e educação.

A cultura visual do cotidiano pode ser disseminada através do ensino de arte voltado para os conhecimentos das linguagens, dos estilos e dos movimentos estéticos das civilizações. As manifestações artísticas estudadas em sala de aula não devem ser encaradas como uma produção do passado, na qual tudo é muito distante dos dias de hoje e da vida dos alunos, mas, na medida do possível, os currículos the devem atribuir as prováveis relações com a demanda cultural condizente com o cotidiano do aluno.

Assim, ao nos deixarmos guiar por referências visuais canonizadas, acervos imagéticos estabelecidos e legitimados, sem considerar o repertório e as experiências visuais dos alunos, funcionamos com disposições automatizadas, sem a preocupação em criar espaços de diálogo, ou seja, sem buscar compreender onde eles (alunos), e nós (professores), situamos/localizamos nossos modos de ver e compreender nossas relações pedagógicas com o mundo, com a aprendizagem, com a escola, com a cultura visual, afinal.

Os componentes curriculares dos PCNs (BRASIL,1998b) trazem definições acerca das áreas do conhecimento (validados pela lei), o que inclui a especificação de conteúdos e objetivos; de critérios e orientações para o processo de avaliação; assim como de orientações didáticas para o tratamento de cada área, a partir, inclusive, dos temas transversais. Deste modo, as questões sociais presentes nos temas transversais (ética; meio ambiente; orientação sexual; saúde; trabalho, consumo e cidadania; pluralidade cultural) nos Parâmetros Curriculares Nacionais devem estar vinculadas à Proposta triangular. Assim, a elaboração do currículo do ensino da arte constitui-se em um espaço de reflexão e diálogo, possibilitando aos 
e-Mosaicos - Revista Multidisciplinar de Ensino, Pesquisa, Extensão e Cultura do Instituto de Aplicação Fernando Rodrigues da Silveira (CAp-UERJ)

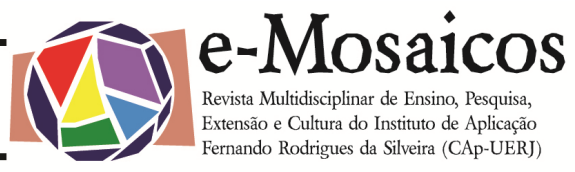

alunos entender e posicionar-se diante de conteúdos artísticos, estéticos e culturais, incluindo as questões sociais. Estes temas são propostas transdisciplinares, em que há um modo de pensar organizador que pode atravessar as disciplinas e que pode dar uma espécie de unidade. Assim, a arte na escola, através da abordagem dos temas transversais, pode contribuir para que os alunos exercitem suas cidadanias e responsabilidades pela formação de uma sociedade mais digna, sem exclusão de pessoas por preconceito de qualquer ordem.

O tema pluralidade cultural (BRASIL, 1997) tem relevância especial no ensino da arte, pois permite ao aluno lidar com a diversidade de modo favorável na arte e na vida. Entretanto, Ana Mae lembra que o termo mais apropriado é "interculturalidade: enquanto os termos multicultural e pluricultural significam a coexistência e mútuo entendimento de diferentes culturas, na mesma sociedade, o termo intercultural significa a interação entre as diferentes culturas" (BARBOSA, 1998, p.14). O sentido interculturalista amplia a discussão sobre a função da arte e o papel do artista em diferentes culturas, assim como o papel de quem decide o que é arte. Celebra-se a diversidade ética e cultural, potencializando o orgulho pela herança cultural de cada indivíduo, seja resultante de processos de erudição quanto do âmbito popular. Problematizam-se acerca de conceitos como etnocentrismo, estereótipos culturais, preconceitos, discriminação e racismo. Enfatiza-se o estudo de grupos das minorias do ponto de vista do poder, como mulheres, homossexuais, índios, negros, deficiente físico e mental, entre outros. Procura-se trabalhar com a diversidade, buscando a igualdade na diferença. Neste sentido, como mencionamos no início, a arte passa a trabalhar com a estética do cotidiano, entrecruzando arte erudita e popular. Refletir sobre a pluralidade cultural, além de ressaltar as especificidades estéticas, contribui para o respei- to assim como torna apreensível as experiências, posições e saberes do outro, valorizando a formação crítica e o desenvolvimento da criatividade. As possibilidades de experiências educativas com imagens são múltiplas e dinamizam seus significados plurais.

Assim, os parâmetros curriculares indicam a linha geral de atuação, a concepção pedagógica geral que se espera para todas as escolas do país, com um ensino centrado no desenvolvimento de competências e habilidades, contextualizado e formador do cidadão. É uma proposta flexível que pode inspirar a prática do professor. Com as novas diretrizes, fica mais clara a responsabilidade da escola e do professor - de estruturar o seu programa de ensino de acordo com a realidade do aluno. O professor, como afirma Ferraz e Fusari (1993, 2010), deve ser um professor-pesquisador-propositor. $\mathrm{O}$ professor é um mediador do processo do ensino-aprendizagem e a relação se desenvolve no diálogo entre professor-aluno. Fusari, ao tratar sobre a seleção de conteúdos em Arte, e, também da postura do professor, evidencia que "para desenvolver um bom trabalho de Arte o professor precisa descobrir quais são os interesses, vivências, linguagens, modos de conhecimento de arte e práticas de vida de seus alunos" (FERRAZ; FUSARI, 2010, p. 71). Esses conhecimentos, imprescindíveis para a prática pedagógica, serão a base na construção dos pilares para uma educação em Arte. Os parâmetros entendem a "caracterização da área de Arte" como uma educação com fundamentos para o desenvolvimento do pensamento artístico e da percepção estética, que caracterizam um modo próprio de ordenar e dar sentido à experiência humana: o aluno desenvolve sua sensibilidade, percepção e imaginação, tanto ao realizar formas artísticas quanto na ação de apreciar e conhecer as formas produzidas por ele e pelos colegas, pela natureza e nas diferentes culturas. (PCNs, 1997, p. 19) 
e-Mosaicos - Revista Multidisciplinar de Ensino, Pesquisa, Extensão e Cultura do Instituto de Aplicação Fernando Rodrigues da Silveira (CAp-UERJ)

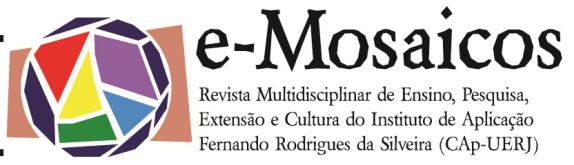

Assim, percebemos que um dos fundamentos destacados pelos PCNs, para a educação das artes, é a prática artística dos alunos. Prática esta, nos parece, indissociável ao conhecimento da cultura visual (e vice-versa). Acredita-se que o aluno, enquanto um cidadão, deve estar predisposto a reconhecer a importância e as particularidades da cultura visual à sua volta, assim como perceber e respeitar crítica e criteriosamente as diversas expressões e manifestações artísticas do cotidiano, incluindo-se como um experimentador-criador visual.

No entanto, deve-se mensurar que a prática artística, reentrante no ensino das artes em muitas escolas, ainda recorre a exercícios e técnicas livres absortas às articulações temáticas e conteúdos curriculares relacionados às especificidades da historiografia da arte - e da cultura visual da contemporaneidade. A experiência visual ainda é desenvolvida como etapas de processos do fazer artístico desprovidos de uma reflexão teórica, da leitura e contextualização da imagem. O ensino muitas vezes ainda se restringe ao conhecimento da arte afora ao Brasil, ou seja, a ênfase à arte internacional desarticulada com as prováveis referências e especificidades culturais brasileiras. Dito de outra forma, o ensino nas escolas mantém-se distante das repercussões com o cotidiano escolar e cultural do aluno. Em muitas escolas, e para muitos alunos, a concepção das aulas de artes se deve às propostas livres de conteúdos específicos ou com pouca finalidade, nas quais são realizadas atividades práticas que não reprovam ou que não estão ligadas a uma fundamentação curricular. As aulas muitas vezes constituem uma aula descontraída, na qual o espaço diferenciado da sala de aula, e o manuseio de diferentes materiais, culminam numa aula dinâmica e interativa- características positivas, porém, desligadas da inter e multidisciplinaridade devidas, e, sobretudo, da cognição. Os educadores continuam tratando a matéria de artes como "rea- lização de atividades agradáveis, de vistoso resultado e perseguindo um tipo de beleza vinculado a uma visualidade formal, e não em termos do processo de aprendizagem ou do novo conhecimento que querem promover" (HERNÁNDEZ, 2000, p. 87).

Nesse contexto, é o momento de iniciarmos uma reformulação curricular com fundamentos balizados na atualização de procedimentos metodológicos mais dinâmicos e condizentes com a cultura visual do cotidiano da contemporaneidade. Assim, na elaboração do currículo, se busca um programa dinâmico, que não esteja preso a moldes pré-formados ou seguindo rigidamente um livro didático, que esteja sempre sendo avaliado pelos professores, pelos alunos e pela escola. Um programa que esteja de acordo com a realidade local e com as necessidades imediatas dos alunos.

Para a elaboração do currículo em artes, torna-se relevante reportarmo-nos aos estudos da cultura visual que surgem nos anos 60, na Universidade de Birmingham, Reino Unido, e que têm por base o termo de Indústria Cultural. A literatura contemporânea, que estuda sobre a cultura visual, se refere à pesquisa da imagem (incluindo-se a obra de arte) e às finalidades de suas questões culturais emergentes. Além dos ingleses, alguns autores propõem os estudos de Roland Barthes (2006), Walter Benjamin (1982), Michel Foucault (1988), Jean Baudrillard (1990, 1991), Guy Debord (1997) como referências para os novos especialistas dos estudos sobre cultura visual. Os temas abordados na cultura visual se deslocam através da reprodução da imagem, da sociedade do espetáculo, do simulacro, do fetiche, das representações do outro, do conceito de Biopoder. Assim, os professores podem estimular os alunos a explorar as representações da cultura visual de uma perspectiva inter ou transdisciplinar, de acordo com diferentes teorias sociais e 
e-Mosaicos - Revista Multidisciplinar de Ensino, Pesquisa, Extensão e Cultura do Instituto de Aplicação Fernando Rodrigues da Silveira (CAp-UERJ)

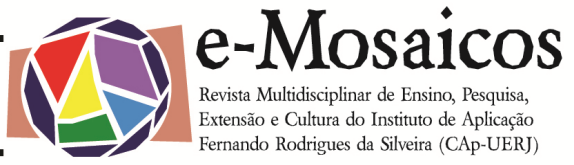

interpretações, considerando a representação visual como uma questão de convenções que se define por suas condições históricas de origem e recepção (BARBOSA, 1998, p.13). Néstor Canclini lembra que há uma intermediação da produção artística e o meio social, fazendo que a produção artística receba interferência do meio socioeconômico. Ressalta Canclini:

A distinção entre as obras de arte e os demais objetos, e a especificação da atitude estética adequada para captar o 'artístico' são o resultado de convenções relativamente arbitrárias, cuja única 'legitimidade' é dada pelas necessidades do sistema de produção e pela reprodução das atitudes consagradas como estéticas pela educação (CANCLINI, 1980 , p. 12).

Neste sentido, Canclini ressalta a problemática das condições históricas de origem e recepção, lembrando que a cultura visual é fruto de convenções. Assim, é importante que o aluno se torne crítico em relação a essa problemática. A cultura visual diz respeito às atuações e experiências de vida na contemporaneidade relacionadas, inclusive, às possibilidades de articulações críticas. Na sala de aula, tanto por parte dos alunos, como a partir da orientação do professor, o ensino da cultura visual aproxima as múltiplas e atuais imagens - nos que diz respeito aos seus meios e processos - com o propósito de suscitar nos alunos suas possíveis articulações e questionamentos ligados à cidadania.

A cultura visual contemporânea na sala de aula solapa as fronteiras entre a cultura popular e a cultura erudita; articula os conceitos midiáticos; pronuncia as diversas ligações entre a experiência estética dos alunos e a epistemologia da arte em diálogos intermitentes entre a vida cultural dos alunos e as relações possíveis com a arte. Sendo assim, no que concerne ao ensino de artes, a apreciação e a reflexão de conceitos da/na contemporaneidade não devem atuar no currículo apenas como finalidades; de mesma forma como a arte, propriamente dita, não deve ser apenas um meio para tal fim.

A composição e atualização dos componentes curriculares para o ensino de artes, todavia, deve atentar para a consideração dos estudos da contemporaneidade, tais como os eventos culturais itinerantes na cidade, como as exposições de arte e seus objetos culturais; os filmes cinematográficos e os reflexos no cotidiano; a preservação do patrimônio cultural; os grafites e demais manifestações expostas nos muros das ruas; assim como os cartazes, os anúncios e as fotografias publicitárias e suas relações midiáticas; da mesma forma nos muitos objetos recorrentes no cotidiano; os jogos eletrônicos; os aplicativos; enfim, estas e todas as demais relações entre arte e vida; entre cidadania e cultura (e vice-versa).

O papel da cultura visual, para Hernández, é observar a "relevância que as representações visuais e as práticas culturais têm dado ao 'olhar' em termos das construções de sentido e das subjetividades no mundo contemporâneo" (HERNÁNDEZ, 1999, p. 27). Articulações sensoriais das mídias, por exemplo, suscitam uma realidade artificial que se propaga através das imagens e textos em um mundo virtual que se torna complementar na articulação de seus elementos ao suplantar as massificações que as tecnologias mencionam e conquistam.

Articular os diálogos entre as pesquisas atuantes na cultura visual contemporânea pode ser um fio condutor para as interlocuções com a historiografia da arte no âmbito nacional e internacional; assim como incitar o juízo crítico é suscitar os alunos a re-pensar os conceitos predominantes e que nem sempre são os incondicionais. $\mathrm{O}$ conhecimento em artes, iniciado com a cultura visual contemporânea, ex- 
e-Mosaicos - Revista Multidisciplinar de Ensino, Pesquisa, Extensão e Cultura do Instituto de Aplicação Fernando Rodrigues da Silveira (CAp-UERJ)

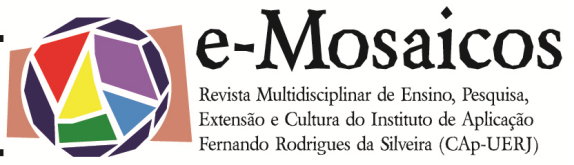

pande o currículo em fundamentos que podem ser dinamizados e que deixa de ser relacionado estritamente com as culturas que parecem distantes e pouco interessantes para os alunos.

A pluralidade das obras visuais contemporâneas, sem dúvida, amplia as experiências estético-plásticas na sala de aula, uma vez que aspectos como a efemeridade e o hibridismo das especificidades da cultura visual alastram as formas de significação dos aspectos culturais, mesmo que entendidos de modo subjetivo. A fragmentação, a globalização e as identidades plurais da cultura da contemporaneidade instigam o debate acerca de uma prática educacional voltada à diversidade cultural e artística. Tais mecanismos metodológicos para o ensino de artes voltam-se sobre o contexto contemporâneo que é determinante para os agenciamentos imperativos do nosso tempo.

A justificativa de uma nova (outra) abordagem do ensino das artes está estritamente relacionada aos objetivos do ensino atual. Nas tendências contemporâneas do ensino de artes, as finalidades da educação vão além do desenvolvimento da sensibilidade, da criatividade, da percepção estética, da fruição, da contemplação e da leitura formal, como se pôde constatar nos seus fundamentos. Nas tendências pedagógicas contemporâneas em Arte e Educação, as finalidades do ensino tornam-se mais amplas, complexas e mais alinhadas com os objetivos de toda a educação escolar, em geral.

Desta forma, a importância de considerarmos a cultura visual contemporânea que se volta prontamente para o cotidiano; para as manifestações das ruas e dos grupos minoritários; assim como para os filmes, as propagandas em TV, revistas e demais veículos de comunicação; enfim, para as manifestações estético-visuais emergentes ao nosso tempo. A educação em arte pode contribuir para que 0 aluno interaja com as produções dos artistas e com a História da Arte, com a cultura de massa, com o mercado mercadológico e midiático, com a política e com as revoluções tecnológicas. Torna-se preciso difundir que a cultura visual, e nesse caso não somente a contemporânea, não se restringe a repercutir objetos, ideias ou conceitos, mas que a particularidade de cada expressão artística é o registro atemporal da necessidade do artista de expressar suas poéticas e de proclamar sua subjetividade. $O$ conhecimento e a contextualização da produção artística na educação estética através do ensino de artes permitem-nos adentrar no tempo/espaço histórico do homem, no seu modo de interpretar o mundo e na sua poética estéticovisual.

Sendo assim, os fundamentos conceituais específicos da área de arte nos levam a constatar que a cultura visual da contemporaneidade deve (e pode) incitar um ponto de apoio para que as filosofias e metodologias de trabalho possam ser desenvolvidas a partir da reflexão de uma práxis artística mais condizente com as questões e inflexões do ensino da atualidade.

A cultura visual da contemporaneidade propicia a diversidade de caminhos investigativos assim como a experimentação de novos materiais e temas em soluções visuais relativizadas pela efemeridade e transitoriedade culturais. A possibilidade de inventar e de atribuir novos significados ao mundo é tão ampla quanto nossa capacidade de apreender e proclamar novos significados, mesmo que tudo, aparentemente, já tenha sido lançado e ditado.

Logo, não é apenas a cultura visual mais relevante no cotidiano do aluno que deve ser considerada, mas a percepção sobre o seu cotidiano, como este se caracteriza para além dos padrões dos quais fomos conduzidos a ponderar e conceber tudo a nossa volta. Torna-se urgente expandir os modelos citados insistentemente para que se consiga aprofundar as ques- 
tões que reverberam na visualidade contemporânea. Para tanto, é preciso dar subsídios estéticos para que os alunos conjuguem os significados anteriores à própria imagem; entendam que os aspectos éticos e estéticos que o cercam são variáveis para os valores subjetivos de determinados comportamentos expressivos. Desse modo, entende-se que a cultura visual contribui para contextualizar e problematizar o consumo imagético; para relacionar as imagens e seus modos expressivos.

Em se tratando do espaço da escola, o compromisso do professor está em lançar o conhecimento acerca das imagens do cotidiano e estabelecer as devidas relações com a cultura visual a fim de despertar as apropriações visuais e os comportamentos diferenciados. A cultura visual conjura valores, reelaborações, interfaces e relações que formam saberes e intensidades, ao buscar-se qualificar a experiência humana por obras, processos e práticas que influenciam os modos de ver e, respectivamente, as formas de compreensão da vida social.

O ensino de arte na escola precisa, assim, considerar esse cotidiano que acontece fora da escola, mas que faz parte do cotidiano dos alunos. Não é possível observar e perceber o aluno, o que ele pensa e constitui e, ainda, como se expressa, se eliminarmos tudo o que Ihe é mais pertinente no seu dia a dia. Somente a partir dessas imagens que estão inseridas no olhar e no imaginário desses alunos é que o professor deve organizar suas práticas curriculares do ensino de artes.

A cultura visual e os referenciais advindos da mídia compreendem as manifestações imagéticas e multiculturais de nosso tempo, o que requer uma postura mais do que interdisciplinar, mas transdisciplinar, ou seja, capaz de romper com os disciplinamentos impostos por modelos racionalizantes, sejam éticos, estéticos ou epistemológicos. E, assim, abandonar os modelos e padrões a que temos sido submetidos para criar/ousar em direção a um mundo mais dinâmico e integrador com a cultura visual da contemporaneidade.

\section{REFERÊNCIAS BIBLIOGRÁFICAS}

BARBOSA, Ana Mae. A imagem no ensino da arte: anos 1980 e novos tempos. São Paulo: Perspectiva, 2012.

. (org.). Arte-educação: leitura no subsolo. São Paulo: Cortez, 2013.

- (Org.) arte/educação contemporânea - Consonâncias internacionais. São Paulo: Cortez, 2006.

John Dewey e o ensino da arte no Brasil. São Paulo: Cortez, 2011.

. Tópicos e Utópicos. Belo Horizonte: C/Arte, 1998.

BARTHES, Roland. Elementos de semiologia. São Paulo: Cultrix, 2006.

BAUDRILLARD. Jean. A transparência do mal: Ensaio sobre os fenômenos extremos. Campinas: Papirus, 1990.

. Da sedução. Campinas: Papirus, 1991.

BENJAMIN, Walter. Obras escolhidas. Vol.1,2 e 3. São Paulo: Brasiliense, 1982.

BRASIL. Secretaria de Educação Fundamental. Parâmetros Curriculares Nacionais: Terceiro e Quarto Ciclos do Ensino Fundamental: Introdução aos Parâmetros Curriculares Nacionais/ Secretaria de Educação Fundamental. Brasília: MEC/SEF, 1998a.

Parâmetros curriculares nacionais: terceiro e quarto ciclos: apresentação dos temas transversais / Secretaria de 
Educação Fundamental. Brasília: MEC/SEF, 1998b.

. Parâmetros curriculares nacionais: apresentação dos temas transversais, pluralidade cultural / Secretaria de Educação Fundamental. Brasília: MEC/SEF, 1997.

CANCLINI. Néstor García. A socialização da Arte: teoria e prática na América Latina. São Paulo: Cultrix, 1980.

- Culturas Híbridas: estratégias para entrar e sair da modernidade. São Paulo: Editora da Universidade de São Paulo, 2011.

DEBORD, Guy. A sociedade do espetáculo. Rio de Janeiro: Contraponto, 1997.

FERRAZ, Maria Heloisa, FUSARI, Maria de Rezende. Arte na educação escolar. São Paulo: Cortez, 2010.

Metodologia do ensino da arte.

São Paulo: Cortez, 1993.

FREIRE, Paulo. Pedagogia do Oprimido. Rio de Janeiro: Paz e Terra, 2005.

FOUCAULT, Michel. História da sexualidade I: a vontade de saber. Rio de Janeiro: Edições Graal, 1988.

HERNÁNDEZ, Fernando. Cultura Visual, mudança educativa e projeto de trabalho. Porto Alegre: Artes Médicas sul, 2000.

Pesquisar com imagens, pesquisar sobre imagens: revelar aquilo que permanece invisível nas pedagogias da cultura visual. In: MARTINS, Raimundo;

TOURINHO, Irene (Orgs.). Processos e práticas de pesquisa em cultura visual $e$ educação. Santa Maria: Editora UFSM, 2013.
- Transgressão e mudança na educação: os Projetos de Trabalho. Porto Alegre: ARTMED, 1999.

MARTINS, M.C. et. al. Didática do ensino de arte. A língua do mundo: poetizar, fruir e conhecer arte. São Paulo, FTD, 1998. 